\title{
EFFECTIVENESS OF WET COMBING COMPARED WITH 1\% PERMETHRIN LOTION FOR THE TREATMENT OF PEDICULOSIS CAPITIS
}

\section{SALEHA SUNGKAR, YASMINE A. DWINASTITI, ROSE A. HASWINZKY, FANNY P. IRMAWATI, AJI W. WARDHANA, PRATIWI SUDARMONO, STANLEY BUNTARAN*}

\author{
Departement of Parasitology Faculty of Medicine, Universitas Indonesia
}

Email: ignatius.stanley@gmail.com

Received: 12 Dec 2018, Revised and Accepted: 10 Mar 2019

\section{ABSTRACT}

Objective: Pediculus humanus capitis is an ectoparasite that sucks blood from the patient's scalp. Gamma-hexachlorocyclohexane is an effective treatment but its use has been discontinued because of its neurotoxicity. Although the replacement pediculicide is permethrin, this is not affordable for everyone, and thus the recommended treatment is wet combing. The aim of this study is to evaluate the effectiveness of permethrin compared with wet combing for eliminating pediculosis.

Methods: This study was a randomized controlled trial (RCT) conducted in a boarding school in Bogor District; the data were collected in JulyAugust, 2018. Subjects were regarded as infested if lice were found during examination. Infested subjects were divided into two groups. In the permethrin group, the hair was wetted with permethrin lotion and left for $10 \mathrm{~min}$. Afterwards, a fine-toothed comb was used to remove lice, and then the subjects were instructed to wash their hair with shampoo. On day 14, each subject's head was reexamined to determine the cure rate. The wet-combing group was treated similarly but using conditioner instead of permethrin.

Results: Of 121 subjects, $88.4 \%$ were infested with head lice. The cure rate after one week of treatment was $66 \%$ in the permethrin group and $63 \%$ in the wet-combing group. After a two-week course of treatment, the cure rate increased to $94 \%$ in permethrin group and $89 \%$ in the wet-combing group. There was no significant difference in cure rate between permethrin and wet combing after a one- $(P=0.740)$ or two-week $(P=0.507)$ course of treatment.

Conclusion: The prevalence of pediculosis capitis in a boarding school in Bogor District was 88.4\%. Wet combing treatment was as effective as permethrin for treating pediculosis capitis.

Keywords: Pediculosis capitis, Wet combing, Permethrin, Treatment, Children

(C) 2019 The Authors. Published by Innovare Academic Sciences Pvt Ltd. This is an open access article under the CC BY license (http://creativecommons. org/licenses/by/4. 0/) DOI: http://dx.doi.org/10.22159/ijap.2019.v11s6.33570

\section{INTRODUCTION}

Pediculosis capitis is a disease caused by infestation of hair and/or scalp by Pediculus humanus capitis (head lice) [1]. This disease is widely distributed worldwide, particularly in school-age children in developing countries. The risk factors are overcrowded housing, low economic status, and poor hygiene [2, 3]. Therefore, pediculosis is commonly found in children living in a dormitory, orphanage, or boarding school with a high number of students in a single classroom.

P. h. capitis is a blood-sucking arthropod that infects the scalp [1] During blood suction, the louse secretes a substance that irritates the scalp tissues and causes erythematous papules accompanied by high intensity pruritus [2]. The sensation of itchiness makes the patient scratch the affected area, thus excoriation may occur followed by the appearance of pustules caused by secondary bacterial infection [5]. Severe infection may lead to pyoderma, ulcer, impetigo, or furuncles $[2,5]$. These symptoms make the hair look dull and sticky, and the hair tends to fall out easily and be easily infected by fungi; this may lead the patient to be shy and have a low level of confidence. Enlargement of lymph nodes and hematologic abnormalities such as monocytosis, eosinophilia, and microcytic hypochromic anemia may also occur $[4,5]$.

Topical treatment is the therapy of choice to eradicate the lice [6]. The aim of treatment is to eliminate the lice by directly killing or removing the lice and preventing their eggs from hatching [6]. A pediculicide is the most effective treatment for pediculosis capitis [6]. The most commonly used pediculicide has been gammahexachlorocyclohexane (BHC) [7]; however, BHC use has been discontinued because of its neurotoxicity and the environmental damage it causes [8]. Therefore, another method is needed to eradicate pediculosis.

The current drug option to eliminate head lice is permethrin in the form of a lotion, but because it is not affordable for everyone, eradication of head lice is often performed manually with a comb [4 $6]$. The use of a wet comb is a low-cost method feasible for use by all communities, but its effectiveness compared with that of permethrin lotion is unknown. However, the manual combing method is time consuming and its cure rate is low. The most recently recommended method is to use a wet comb on hair wet with conditioner or coconut oil, which ensures that the lice stick to the wet comb $[4,9]$.

The aim of this study was to evaluate the effectiveness of permethrin compared with wet combing. The study was conducted in Pamijahan village, Bogor District, because of its high prevalence of pediculosis in schools with large student populations.

\section{MATERIALS AND METHODS}

This study was a randomized controlled trial (RCT) that was preceded by a cross-sectional study to recruit research subjects at a boarding school, Pamijahan village, Bogor District, from July-August 2018. A total of 121 female students who agreed to join the study were examined for head lice infestation. Female students infested with $P$. h. capitis were treated with permethrin or told to comb their hair using the wet comb method for 14 consecutive days. Students who were sick or suffered from severe pediculosis were excluded from this study. The study was approved by the Ethics Committee of the Health Research Faculty of Medicine, Universitas Indonesia, with ethics approval No. 0856/UN2. F1/ETIK/2018.

\section{DATA COLLECTION}

Female students were examined to diagnose pediculosis by detection of the eggs, larvae, nymphs, or adult lice on their hair and/or scalp. Subjects were defined as infested if adult lice, larvae, or nymphs were found; infested subjects were divided into two groups: the permethrin group and the wet-comb group.

For the permethrin-treated group, the hair was initially combed with a loose comb to untangle it, and then washed with permethrin 
lotion until all the hair was moist. Next, an antilice comb was used to remove any larvae, nymphs, or adult lice. Subjects were asked to leave the permethrin lotion on their hair for 10 min after application and then to wash their hair with shampoo. On day 14, each subject's head was reexamined to determine the cure rate and subjects who still had pediculosis infestation were retreated with permethrin.

For the wet-comb-treated group, the subject's hair was first combed with a loose comb to untangle it, and then the hair was washed with conditioner and combed with an antilice comb to remove any larvae, nymphs, and adult lice. Students were then asked to wash their hair with shampoo. All students were given the loose comb, fine-tooth comb, and conditioner to take to their dormitory and instructed to repeat the procedure every day for $14 \mathrm{~d}$. To determine the cure rate, they were examined on day 14 and subjects who were still infested with pediculosis were given permethrin.

\section{DATA ANALYSIS}

To determine the difference in cure rate between the groups, the data were analyzed using the chi-squared test and the Fischer test if the requirements for chi-squared testing were not fulfilled. A $P$ value $<0.05$ was considered significant. Associations were evaluated using relative risk (RR) with 95\% confidence interval (CI). Treatment was considered effective if $>90 \%$ of the subjects were cured and the cure rate was calculated using the following formula:

(Number of cured pediculosis capitis subjects/Number of treated pediculosis capitis subjects) $\times 100$.

All data were processed and analyzed with SPSS statistical software version 20

\section{RESULTS}

Table 1 shows the prevalence of children suffering from pediculosis capitis. Of all subjects examined $(\mathrm{n}=121), 107(88.4 \%)$ were positive for pediculosis capitis infestation and 110 (90.9\%) were found to have nits on their head. It also can be seen that younger subjects had a higher likelihood of being infested with lice or nits.

Table 1: The prevalence of pediculosis capitis in boarding school students by age

\begin{tabular}{llll}
\hline Age (years) & Lice & $\mathbf{9 5 \%}$ CI & Nits \\
\hline $9-12(\mathrm{n}=46)$ & $42(91.3 \%)$ & $80.3-97.2$ & $42(91.3 \%)$ \\
$13-18(\mathrm{n}=75)$ & $65(86.6 \%)$ & $77.5-93.0$ & $68(90.6 \%)$ \\
Total $(\mathrm{n}=121)$ & $107(88.4 \%)$ & $81.8-93.3$ & $110(90.9 \%)$ \\
\hline
\end{tabular}

Children who tested positive for head lice infestation were divided into two groups to receive different treatments. The first group was treated with $1 \%$ permethrin lotion and the second using the wet-combing method. Table 2 shows that the proportion of subjects with lice was reduced by both methods of treatment. After one week of treatment, $35(66 \%)$ of subjects from the permethrin group and $34(63 \%)$ of those from the wet-comb group were cured of head lice; there was no significant difference in these cure rates $(P=0.740)$. After two weeks of treatment a cure rate of $94 \%$ was achieved in the permethrin group and $89 \%$ in the wet-comb group; these cure rates were not significantly different (chi-squared test, $P>0.05$ ).

Table 2: Proportion of subjects with lice before and after intervention

\begin{tabular}{llll}
\hline Evaluation & Intervention & Wet Comb & P-value \\
\cline { 2 - 4 } & Permethrin & $54(100 \%)$ & \\
\hline Before (baseline) & $53(100 \%)$ & $20(37 \%)$ & 0.740 \\
After one week & $18(34 \%)$ & $34(63 \%)$ & 0.507 \\
Cured & $35(66 \%)$ & $6(11 \%)$ & \\
After two weeks & $3(6 \%)$ & $48(89 \%)$ & \\
Cured & $50(94 \%)$ & & \\
\hline
\end{tabular}

\section{DISCUSSION}

This study aimed to compare the effectiveness of wet combing with that of $1 \%$ permethrin lotion for the treatment of pediculosis capitis. School-age children were selected as the study sample because previous studies have suggested that pediculosis capitis is one of the most prevalent communicable diseases in school-age children [15, 16]. In addition, this study was conducted in a boarding school that had a high prevalence of head lice infestation. The high number of students, who commonly share rooms, clothes, and towels, facilitated transmission of head lice infestation among the children [17]. We only studied girls as they are more susceptible than boys because of their longer hair [18].

The prevalence of lice infested students in this study was $88.4 \%$ and nits were found in $90.9 \%$ of students. This rate of infestation with head lice is very concerning because it is higher than those reported for similar studies among school-age children [19-22]. A higher proportion of younger children were infested with both head lice and nits, which is consistent with a previous study in Peru by Leeshaft et al. [21] that reported that children $<12$ y old had higher proportion of head lice infestation than older children (0-11 y $64.7 \%$ vs. $\geq 12$ y $15 \%$ ).

In terms of head lice treatment, we only evaluated the effect on head lice and nits that were located less than $0.5 \mathrm{~cm}$ from the scalp (indicates current infection). Nits located more than $0.5 \mathrm{~cm}$ from the scalp were not included because they had already hatched and represented past infection.

This study found that wet combing and $1 \%$ permethrin lotion had similar efficacy for reducing the proportion of subjects infected with head lice, with no significant difference between the cure rates of both treatments. The wet-combing method was considered for evaluation because compared with permethrin it is more affordable, more readily available, and easier to do, especially in rural areas. The results of our study were similar to those of a study in the United Kingdom that found no significant difference in outcomes between wet combing and phenothrin lotion (a synthetic pyrethroid similar to permethrin) [22].

Interestingly, contradictory results were obtained in a study that showed that wet combing (bug buster kit) was significantly better than pediculicides (pyrethroid or organophosphate) [23]. However, the comparison with the United Kingdom is not appropriate, because it has been reported that head lice in the UK are resistant to pyrethroids such as permethrin [24]. A similar study in Wales by Meinking et al. [25] yielded similar results to our study. They compared permethrin $1 \%$ as single treatment vs. permethrin $1 \%$ with wet combing, and found that although the effectiveness of wet combing for nit removal after $15 \mathrm{~d}$ use was less than that of $1 \%$ permethrin alone, the proportion of lice-free subjects was similar (wet combing: $72.7 \%, 95 \%$ CI 54.5-86.7; permethrin $1 \%$ alone: 78.3\%, 95\% CI 65.8-87.9). Meinking et al. argued that the lower 
effectiveness of wet combing for eradication of head lice was because nonprofessional caregivers failed to use the comb properly.

The mechanism of action of permethrin is mainly to induce neurotoxicity in lice but not in their nits (nonovicidal). Therefore, the use of permethrin needs to be repeated, usually $7 \mathrm{~d}$ later, to completely eradicate all lice and newly hatched nits [26]. Head lice infestation is most common in school-age children. Therefore, the reinfection rate is high because the children are in close contact almost every day [18]. Repeated use of permethrin may lead to side effects such as pruritus, swelling, or erythema [27]. Wet combing, on the other hand, does not contain insecticide and as our study showed, is as effective as permethrin if used properly and routinely. The similar cure rates seen in our study for wet combing and permethrin $1 \%$ may have been because all children were treated with the wet-combing method at school and under supervision by their teachers for $14 \mathrm{~d}$.

In Indonesia, children are more obedient to their teacher's advice than to their parents. Therefore, if the wet-combing method was used at home under their parents' supervision, the results might not be as effective, because parents in Indonesia often forget to apply the wetcombing method as advised. Therefore, we encourage the use of the wet-combing method to treat head lice under strict supervision by parents or caregivers, because it is not as toxic as pediculides.

\section{CONCLUSION}

both the $1 \%$ permethrin lotion and the wet-combing method were equally effective for the treatment of pediculosis capitis, as demonstrated by their similar high cure rates after $14 \mathrm{~d}$ of treatment.

\section{ACKNOWLEDGEMENT}

This article was presented at The 3rd International Conference and Exhibition on Indonesian Medical Education and Research Institute (ICE on IMERI 2018), Faculty of Medicine, Universitas Indonesia, Jakarta, Indonesia. We thank the 3rd ICE on IMERI Committee who had supported the peer review and manuscript preparation before submitting to the journal.

\section{AUTHORS CONTRIBUTIONS}

All the author have contributed equally

\section{CONFLICT OF INTERESTS}

There are no conflicts of interest

\section{REFERENCES}

1. Mumcuoglu KY. Is the head louse, Pediculus humanus capitis, a vector of human diseases? J Trop Dis 2013;1:e101. DOI:10.4172/2329-891X.1000e101.

2. Abdolhosseini S, Mokaberinejad R, Alian Nezhadi V, Bozorgi M, Nazem E. Evaluation of treatment with squill vinegar in 10 patients with head pediculosis. Asian J Clin Case Rep Trad Alt Mod 2017;1:57-64.

3. Wolff K, Goldsmith LA, Katz SI, Gilchrest BA, Paller AS, Leffell DJ. Fitzpatrick's dermatology in general medicine. $17^{\text {th }}$ ed. New York: McGraw-Hill; 2008. p. 2029-37.

4. Cummings C, Finlay JC, MacDonald JE. Head lice infestations: a clinical update. Paediat Child Health 2018;23:18-24.

5. Sangare AK, Doumbo OK, Raoult D. Management and treatment of human lice. Biomed Res Int 2016. DOI:10.1155/2016/8962685

6. Schenone H, Wiedmaier G, Contreras L. Treatment of pediculosis capitis in children with permethrin $1 \%$ shampoo or lotion. Bull Chil Parasitol 1994;49:49-52.

7. Requirements and steps for pesticide submission. Decision of Agriculture Ministry Republic of Indonesia No: 434.1/ KPTS/TP.270/7; 2001.
8. Hapsari YC. Treatment effectiveness comparison between wet combing and $0.5 \%$ hexachlorocyclohexane lotion on female students with pediculosis capitis in a boarding school in Jakarta. Jakarta [thesis]. Universitas Indonesia; 2013.

9. Tebruegge $\mathrm{M}$, Runnacles J. Is wet combing effective in children with pediculosis capitis infestation? Arch Dis Child 2007;92:818-20.

10. Lacarruba F, Boscaglia S, Dinotta F, Micali G. Pediculosis. Atlas Pediatr Dermatoscopy 2018;9:63-70.

11. Pediculosis [Internet] Atlanta Centers for Disease Control and Prevention; 2017. Available from: https://www.cdc.gov/dpdx/pediculosis/index.html [Last accessed on 27 May 2018]

12. Bohl B, Evetts J, McClain K, Rosenauer A, Stellitano E. Clinical practice updates: pediculosis capitis. Pediatr Nurs 2015;41:227-34.

13. Verma P, Namdeo C. Treatment for pediculosis capitis. Indian J Dermatol 2015;60:238-47.

14. Glasziou P, Bennett J, Greenberg P, Green S, Gunn J, Huffman T. Wet combing for the eradication of head lice [Internet] Melbourne. Australian Family Physician; 2013. Available from https://www.racgp.org.au/afp/2013/march/wet-combing/ [Last accessed on 27 May 2018]

15. Tappeh KH, Chavsin AR, Hajipirloo HM, Khashaveh S, Hanifian $\mathrm{H}$, Bozorgomid A, et al. Pediculosis capitis among primary school children and related risk factors in Urmia, the main city of West Azarbaijan, Iran. J Arthropod Borne Dis 2012;6:79-85.

16. Rassami W, Soonwera M. Epidemiology of pediculosis capitis among schoolchildren in the eastern area of Bangkok, Thailand. Asian Pac J Trop Biomed 2012;2:901-4.

17. Degeril S, Malatyali E, Mumcuoglu KY. Head lice prevalence and associated factors in two boarding schools in Sivas. Turkiye Parazitol Derg 2013;37:32-5.

18. Assaedi LA, Alharbi AH, Aldor SM, Albarakati BA, Alsahafi IK, Magliah RF, et al. The prevalence of pediculosis capitis in makkah city, Saudi Arabia. Our Dermatol Online 2018;9:114-7.

19. Manrique Saide P, Pavia Ruz N, Rodriguez Buenfil JC, Herrera R, Gomez Ruiz P, Pilger D. Prevalence of pediculosis capitis in children from a rural school in yucatan, mexico. Rev Inst Med Trop Sao Paulo 2011;53:325-7.

20. El-Sayed MM, Toama MA, Abdelshafy AS, Esawy AM, El-Naggar SA. Prevalence of pediculosis capitis among primary school students at Sharkia Governorate by using dermoscopy. Egypt J Dermatol Venerol 2017;37:33-42.

21. Leeshafft H, Baier A, Guerra H, Terashima A, Feldmeier H. Prevalence and risk factors associated with pediculosis capitis in an impoverished urban community in Lima, Peru. J Glob Infect Dis 2013;5:138-43.

22. Burgess IF, Brown CM, Nair P. Comparison of phenothrin mousse, phenothrin lotion, and wet-combing for treatment of head louse infestation in the UK: a pragmatic randomized, controlled, assessor blind trial. F1000 Res 2014;3:158.

23. Hill N, Moor G, Cameron MM, Butlin A, Preston S, Williamson MS, et al. Single blind, randomized, comparative study of the bug buster kit and over-the-counter pediculicide treatments against head lice in the United Kingdom. Br Med J 2005;331:384-7.

24. Dodd C. Treatment of head lice. Br Med J 2001;323:1084.

25. Meinking TL, Clineschimdt CM, Chen C, Kolber MA, Tipping RW, Furtek CI, et al. An observer-blinded study of $1 \%$ permethrine creme rinse with and without adjunctive combing in patients with head lice. J Pediatr 2002;141:665-70.

26. Lebwohl M, Clark L, Levitt J. Therapy of head lice based on life cycle, resistance, and safety considerations. Pediatrics 2007;119:965-7.

27. Devore CD, Schutze GE. Head lice. Pediatrics 2015;135:1355-8. 